\title{
Single cell analysis informing therapy response in hepatocellular carcinoma and intrahepatic cholangiocarcinoma
}

\author{
Daniel Wai-Hung $\mathrm{Ho}^{1,2}$, Irene Oi-Lin $\mathrm{Ng}^{1,2}$ \\ ${ }^{1}$ Department of Pathology, The University of Hong Kong, Hong Kong, China; ${ }^{2}$ State Key Laboratory of Liver Research, The University of Hong \\ Kong, Hong Kong, China \\ Correspondence to: Irene Oi-Lin Ng. Department of Pathology and State Key Laboratory of Liver Research, The University of Hong Kong, Hong \\ Kong, China. Email: iolng@hku.hk. \\ Comment on: Ma L, Wang L, Khatib SA, et al. Single-cell atlas of tumor cell evolution in response to therapy in hepatocellular carcinoma and \\ intrahepatic cholangiocarcinoma. J Hepatol 2021;75:1397-408.
}

Submitted Dec 01, 2021. Accepted for publication Dec 12, 2021.

doi: 10.21037/hbsn-2021-27

View this article at: https://dx.doi.org/10.21037/hbsn-2021-27

Liver cancer is known to have significant degree of intratumoral heterogeneity (ITH) (1). Hepatocellular carcinoma (HCC) and intrahepatic cholangiocarcinoma (ICC) are major forms of primary liver cancer, accounting for $>95 \%$ of cases. ITH is linked, as least in part, to the aggressiveness and refractoriness of liver cancer, rendering its high lethality among human malignancies (2). The complex tumor microenvironment promotes tumor progression and contributes to poor treatment response. Hence, it is vital to address the biological mechanisms underlying liver cancer progression and treatment response analyzing the cells in high resolution rather than the mixture of many cell types. Recent advances in single-cell RNA sequencing (scRNA-seq) provide an avenue to dissect liver cancer in an unprecedented degree of high resolution to characterize the underlying pathogenesis and heterogeneity.

There exist lines of evidence suggesting the involvement of malignant and immune components, as well as their crosstalk in liver cancer. With the emergence of scRNA-seq technologies, HCC and ICC have been investigated using scRNA-seq, with generation of abundant highly useful data. Immune cells, stromal cells and malignant cells are the main constituent elements of HCC and ICC. Among them, the immune cells are regarded as the major contributors to resistance to anti-tumor therapies and tumor clearance. Nonetheless, through the course of tumor progression, the cancer cells could acquire some unique molecular characteristics to enable their effective evasion from the immune surveillance during tumor initiation, and sustain the tumor development at subsequent stages (3). On the other hand, the anti-cancer immunity may acquire transformation, upon the action of specific key genes or signaling pathways, to become tolerant or even supportive to cancer development (4). Recent studies have revealed that HCC immune ecosystem involves myeloid-derived (dendric cells and tumor-associated macrophages), and lymphocyte-derived ( $\mathrm{T}$ cells, B cells, plasma cells, and NK cells) components (5-8), as characterized by the expression of the canonical cell type markers.

ITH or biodiversity of liver cancer has been investigated in the perspectives of cancer stem cells (9) and microenvironmental reprogramming (7). Along this axis, $\mathrm{Ma}$ et al. have advanced their study and recently published their single-cell atlas on HCC and ICC. They reported the tumor cell evolution and the molecular landscape in response to immunotherapy (10). In the study, the authors analyzed 46 HCC and ICC biopsies from 37 patients, in which 16 biopsies were collected before and after immunotherapy from 7 patients. They profiled the transcriptome of 56,721 single cells. Consistent with their and our previous studies $(7,8)$, among the 17,164 malignant cells identified, these cells could be stratified into patient-specific clusters, indicating the prominent inter-patient difference on the malignant component. Notably, using hierarchical clustering algorithm, they searched for similarities among malignant cells of tumors and defined 3 major classes of tumors (BI-A, BI-B and BI-C). BI-A tumors were from HCC cases, while the remaining were either HCC or 
ICC. On the other hand, supportive to the hierarchical clustering results, there was consistent intra-tumoral lineage architecture as revealed by different algorithms. The gene SPP1 (encoding osteopontin) was determined to be a conserved gene in BI-B and BI-C tumors, with elevated expression in the tumor cells and ubiquitous enrichment at branch level. Clonality-high tumors (BI-B and BI-C; with higher numbers of cell clusters within tumors) were suggested to be more diverse and aggressive and resulted in poorer survival of patients. Mechanistically, BI-B and BI-C tumors were enriched in pathways related to epithelialmesenchymal transition, hypoxia, TNF- $\alpha$ signaling and glycolysis. The data collectively suggests the implication of tumor functional clonality in patients' prognostication.

They also examined the non-malignant components and identified different transcriptomic profiles between BI-A and $\mathrm{BI}-\mathrm{B} / \mathrm{C}$ tumors, indicating putative reprogramming of non-malignant cells by malignant cells. Importantly, there was polarization of $\mathrm{T}$ cell subtypes between the BI-A and $\mathrm{BI}-\mathrm{B} / \mathrm{C}$ tumors, accompanied by substantially stronger ligand-receptor interaction between malignant cells and $\mathrm{T}$ cells in BI-B/C tumors than in BI-A ones. SPP1-CD44 was the key interaction pair between malignant cells and $\mathrm{T}$ cells, and this further illustrated the functional role of SPP1 in the tumor ecosystem. Moreover, such polarization pattern could also be observed in other non-malignant cell types, indicating a likely holistic clonal evolution of the tumor microenvironment.

Cellular and molecular landscapes of HCC tumor are likely to be highly dynamic, in response to and exerted by the treatment. By analyzing 4 cases with biopsies, each having sequenced at least 15 malignant cells before and after immunotherapy, they identified 2 cases having obvious stratification of malignant cell lineages after treatment, while the remaining ones displayed admixed pattern. The authors made collective use of the functional clonality, degree of genomic similarity in paired biopsies, and SPP1 expression level to explain the responsiveness of immunotherapy, although they also admitted the limitation of a small sample size with relatively few cell counts on individual cases. Indeed, the findings of their study may provide plausible clues in explaining immunotherapy outcome. However, further studies with larger sample sizes are very much awaited.

Taken altogether, Ma et al. have beautifully revisited the topic of ITH or biodiversity using scRNA-seq technology. While there were previous reports by other groups suggesting the important roles of SPP1 in human cancers including HCC and the crosstalk between SPP1 and CD44 in immune evasion (11-14), of note, this study linked SPP1 expression as potential biomarker in defining subtypes of liver cancer having poorer clinical phenotypes. Compared to the previous report of scRNA-seq study by the same group (7), its major finding of the current report hinges upon the identification of determinants that may govern response to immunotherapy. In the coming future, further translational efforts and clinical reports should be focused on finding the determinants on response to immunotherapy in liver cancer.

\section{Acknowledgments}

Funding: This article was supported by the Hong Kong Research Grants Council (RGC) Theme-based Research Scheme (T12-704/16-R), Innovation and Technology Commission grant for State Key Laboratory of Liver Research, and Loke Yew Endowed Professorship award. IOL Ng is Loke Yew Professor in Pathology.

\section{Footnote}

Provenance and Peer Review: This article was commissioned by the editorial office, Hepatobiliary Surgery and Nutrition. The article did not undergo external peer review.

Conflicts of Interest: Both authors have completed the ICMJE uniform disclosure form (available at https://hbsn. amegroups.com/article/view/10.21037/hbsn-2021-27/coif). The authors have no conflicts of interest to declare.

Ethical Statement: The authors are accountable for all aspects of the work in ensuring that questions related to the accuracy or integrity of any part of the work are appropriately investigated and resolved.

Open Access Statement: This is an Open Access article distributed in accordance with the Creative Commons Attribution-NonCommercial-NoDerivs 4.0 International License (CC BY-NC-ND 4.0), which permits the noncommercial replication and distribution of the article with the strict proviso that no changes or edits are made and the original work is properly cited (including links to both the formal publication through the relevant DOI and the license). See: https://creativecommons.org/ licenses/by-nc-nd/4.0/. 


\section{References}

1. Chan LK, Tsui YM, Ho DW, et al. Cellular heterogeneity and plasticity in liver cancer. Semin Cancer Biol 2021. [Epub ahead of print].

2. Llovet JM, Kelley RK, Villanueva A, et al. Hepatocellular carcinoma. Nat Rev Dis Primers 2021;7:6.

3. Hanahan D, Weinberg RA. Hallmarks of cancer: the next generation. Cell 2011;144:646-74.

4. Gonzalez H, Hagerling C, Werb Z. Roles of the immune system in cancer: from tumor initiation to metastatic progression. Genes Dev 2018;32:1267-84.

5. Sun Y, Wu L, Zhong Y, et al. Single-cell landscape of the ecosystem in early-relapse hepatocellular carcinoma. Cell 2021;184:404-421.e16.

6. Song G, Shi Y, Zhang M, et al. Global immune characterization of $\mathrm{HBV} / \mathrm{HCV}$-related hepatocellular carcinoma identifies macrophage and T-cell subsets associated with disease progression. Cell Discov 2020;6:90.

7. Ma L, Hernandez MO, Zhao Y, et al. Tumor Cell Biodiversity Drives Microenvironmental Reprogramming in Liver Cancer. Cancer Cell 2019;36:418-430.e6.

8. Ho DW, Tsui YM, Chan LK, et al. Single-cell RNA

Cite this article as: $\mathrm{Ho} \mathrm{DWH}, \mathrm{Ng}$ IOL. Single cell analysis informing therapy response in hepatocellular carcinoma and intrahepatic cholangiocarcinoma. HepatoBiliary Surg Nutr 2022;11(1):126-128. doi: 10.21037/hbsn-2021-27 sequencing shows the immunosuppressive landscape and tumor heterogeneity of $\mathrm{HBV}$-associated hepatocellular carcinoma. Nat Commun 2021;12:3684.

9. Zheng H, Pomyen Y, Hernandez MO, et al. Singlecell analysis reveals cancer stem cell heterogeneity in hepatocellular carcinoma. Hepatology 2018;68:127-40.

10. Ma L, Wang L, Khatib SA, et al. Single-cell atlas of tumor cell evolution in response to therapy in hepatocellular carcinoma and intrahepatic cholangiocarcinoma. J Hepatol 2021;75:1397-408.

11. Zhao H, Chen Q, Alam A, et al. The role of osteopontin in the progression of solid organ tumour. Cell Death Dis 2018;9:356.

12. Klement JD, Paschall AV, Redd PS, et al. An osteopontin/ CD44 immune checkpoint controls CD8+ T cell activation and tumor immune evasion. J Clin Invest 2018;128:5549-60.

13. Moorman HR, Poschel D, Klement JD, et al. Osteopontin: A Key Regulator of Tumor Progression and Immunomodulation. Cancers (Basel) 2020;12:3379.

14. Rangaswami H, Bulbule A, Kundu GC. Osteopontin: role in cell signaling and cancer progression. Trends Cell Biol 2006;16:79-87. 